\title{
Preventive and curative importance of the baropodometric analysis for ergonomics and occupational health
}

\author{
Vélez V. Martha Kenny a ${ }^{\text {, Nolivos Verónica }}{ }^{\text {a }}$, Alegría Fabricio ${ }^{a}$ \\ Universidad de las Américas, Quito, Ecuador
}

\begin{abstract}
The pressure distribution on the plantar surface may reveal information not only about the feet structure, also it may bring out information about the entire body posture not only on health but also pathologic conditions. The application in ergonomics and ocupational health gives acces to the postural correction that on a long term may provoke professional injuries giving presition and security. This study is on 132 workers of Universidad de las Américas.
\end{abstract}

Keywords: baropodometric, ergonomics, pressure plantar, body posture, preventive injuries.

\section{Introduction}

Baropodometricity is a registered posture graphic technique, used for the diagnosis and evaluation of plantar pressure, in an static standing position as well as an in motion position which registers points of pressure caused by the body itself. The baropodometric has a barosensible plaque of various dimensions, used in this investigation with piezoelectric sensors distributed in all the surface and connected to a computer; this computer uses an appropriated software used for the visualization of all of the gathered information which will be later printed as graphics and observed in videos as well. It may be useful as a preventive and corrective action in orthopedic physiotherapy as well, traumatology as well as in ergonomics and occupational health.

Within the modern vision of physiotherapy executed and applied to the ergonomics camp, which emphasizes a kinesiology biomechanics diagnosis, we may identify the direct or indirect agents that lead the individual towards corporal imbalance or lack of equilibrium the moment of working or standing up.

There are a lot of workers who complain about the security's boots comfort, especially the ones who work in an 8-hour journey standing and those who travel considerable distances within the working place or exteriors.

The physiotherapist or professional who would integrate the different performance methodologies activities and ergonomic analysis, as well as the standard evaluation tools must perform a functional physiologic diagnosis or a biomechanics diagnosis. The baropodometer is equipment that integrates the diagnosis protocol.

The same way the negatoscope, the reflex hammer or the filament are managed, a baropodemeter must be present in order to obtain diagnostic precision in a single or various position risk factors of the subject and to elaborate precision active "pauses.

\section{General objective}

Ergonomic individual risk analysis for muscleskeletical prevention.

Study of work activities associated with standing and motion.

\footnotetext{
* Corresponding authors e-mail: mvelez@udla.edu.ec vnolivos@udla.edu.ec
} 


\section{Specific objectives}

The general objectives were achieved throughout the execution of the following baropodometric individual evaluations:

Identification of the foot's form: (Egyptian, Greek or roman), of each one of the employees for the correct acquisition of daily and sports footwear.

Identification of the type of plantar arch and its deviations, inside or outside, the foot's balance for the correct prescription of corrective foot beds.

Detection of pressure mismatches in pressure and balance of every person's feet to prevent future injuries.

Prescription of individual prevention programs according to the risk of every person referred to:

a. Deviations in sole pressure.

b. Muscle strength of feet and legs.

c. Articular movement.

d. Alterations of balance on standing position.

e. Circulatory disorders.

f. Footwear type to be used at work and sports practiced.

Identification and proposition of corrective measures not only for inferior member problems that have caused injuries or that may provoke low performance and detection of other aspects like balance that may present a potential risk on a low and mid term.

Prescription for prevention of fatigue and pain of inferior members.

\section{Methods}

This is referred to a transversal study with the current workers at Universidad De Las Américas, people of both sexes, from 18 to 50 years old. People with physical disabilities were excluded.

The exam registers graphically the foot, gathering images based on the individual' $s$ footprint while standing and walking.

The system is made up based on a baropodometric capture platform (that has 2800 active sensors in $120 \mathrm{~cm}$ ) intertwined with capture software.

The installation allows a procedure that may measure the distribution of plantar pressure in an erect position, may it be in an static or dynamic phase providing:

The values of the pressure of each foot in colors.

The images of this pressure in 2D and 3D.

The maximum pressure of the forefoot, midfoot and hind foot.
The support surface of both feet with its individual and regional values.

The barycenter of the body or pressure center projected on the interior of the support polygon.

The barycenter that goes along the perpendicular of each member.

The dynamic barycenter.

The pressure values expressed in $\mathrm{gr} / \mathrm{cm} 2$ allow to reed the plantar map, showing the relationship with a normal static foot, hypo charge or hyper charge zones en case of existing relative values zones to the isobaric level (same charge intensity point) superior or inferior within the area considered and depending on the colors established en relationship with the studies about the normality of the levels of pressure, as the definable charges vary: strong (red), medium (green) levels or moderated (blue).

Therefore the normal static distribution will show a graphic with red on the hind foot bilaterally and centrally, green transversal and bilaterally, in blue, on the lateral borderline on the middle of the foot or the zones nearby in green or red, and light baby blue on the fingers.

It allows registering qualitative data a morphological analysis and the line of progression of the step (trace, direction, uniformity of the progression, etc.) as well as the quantitative data en percentages of the pressure of the anatomic zone of the plantar surface and de support area of every foot, statically and dynamically.

It is possible to reproduce in the video each of the sequences of the sub phases of the motion, with the projection of the gravity line that biomechanically makes each foot, both feet and show graphically the pressure points.

We may be able to have an accelerator or simulator in order to increase the normal cadency or diminish it, simulating a race or a slow march.

\subsection{Analysis procedure}

The employee was put on a platform without shoes, reminding him to assume his natural relaxed position and was also asked to stay still for thirty seconds in order to evaluate de static support.

This support is visualized after the software has calculated the average of the oscillations of the subject during the capture time. Successively the patient was asked to walk over the platform to perform the dynamic exam. The capture starts when the foot touches the platform alternating the charge first with the right foot and then with the left foot. 
The data obtained represents the equilibrium oscillation on the ante posterior and lateral layouts. The instrumentation allows the obtaining of a video with the analysis of the step, also the possibility of developing with a repetition system, with different speeds of the step.

Once the exam is done the static and dynamic impressions were documented in two dimensions as well as in three dimensions, the form of the foot was classified as well: Greek, Egyptian, roman, it's length, number and width.

The biomechanics step videos were analyzed in $2 \mathrm{D}$ and $3 \mathrm{D}$, using the software possibilities to simulate the rhythm from too slow to the simulation of the race.

\subsection{Technical variables of the study}

The technical variables that were established for the individual evaluations were:

\subsubsection{Quantitative variables}

Postural Habit: static or dynamic standing, mixed:

Standing on foot permanence in hours during the work journey.

Walking time during the journey.

Level of pressure in the foot zone: previous, middle, posterior and lateral.

Deviation level of the center of gravity: left, right or centered.

\subsubsection{Qualitative variables}

Foot Characteristics and position on the job:

Foot's form: Greek, Egyptian and roman

Height of the plantar lengthwise arc: plain, normal and high.

Type of working footwear

Foot, ankle and knee position during the performance of specific tasks.

\subsection{Quantitative analysis}

Types Of Foot And Plantar Arc
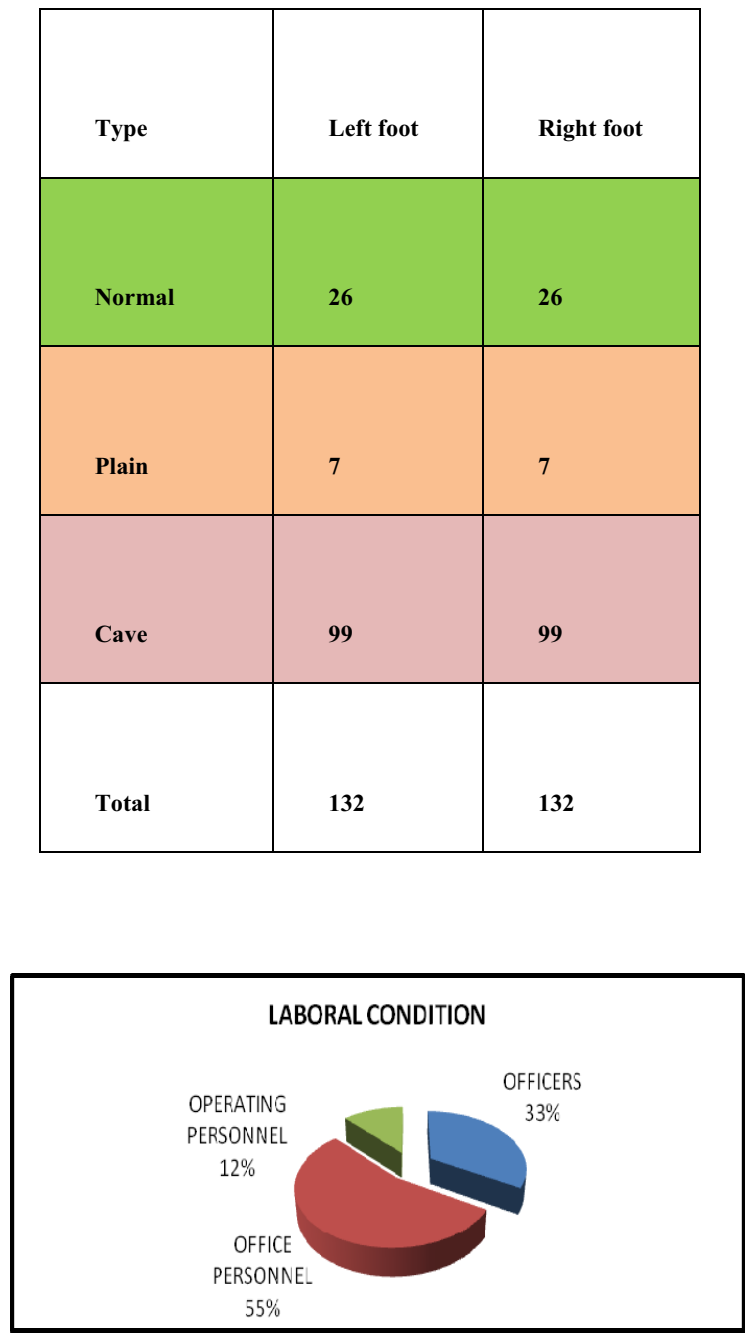

\subsubsection{Other variables \\ Age \\ Sex / Gender \\ Weight \\ Sports practiced}

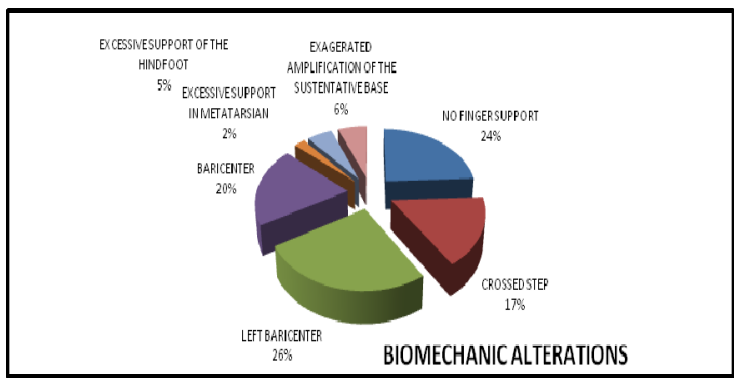




\section{Conclusion}

There is a close relationship between the plantar pressures, the foot form, the plantar arc and the deviations of the inferior segments and the pelvis for the individual's posture.

The shortenings of the hamstring muscles are reflected in the excessive plantar preassure on the hindfoot, the feet and knees valgus and the change in the support fases of the step and the imbalance of the biocinematic chains.

The use of baropodometry in phisiotherapy, ergonomics and ocupational health, gives access to the correct prevention of postural deffects, the pathologies of the foot's charge and the locomotor apparatus with orthopedic type affectations, neurological and diabetological, vascular and of balance.

The application of baropodometry for the prevention and healing of the workers and employees has a high reliability, since it allows to prevent posture deffects that on a long term may provoke professional injuries.

It has the application to improve the foot step, the step motion, the development of laboral tasks, the sports gesture and adquire a satall base more adequate in individual and collective sports.

It serves to prescribe and adapt the individual conditions of the foot, boot or security footwear in relation with the foot's form, the plantar arc, the security toecap, the discharge ones and the elaboration materials.

It is used on exact diagnosis for definitive treatments, precise and instant, repetitive, non invasive, controls with video-image in real time. It compares the steps before and after a treatment, with or without an element of correction, obtainning a precise visutal data of the different support phases.

It allows to amplify and sharpen the observations, giving presition and security in the ergonomic preventive and corrective assistance.

\section{References}

[1] Amadio AC, Sacco IC. Considerações metodolócas da biomecânica para a avaliação da distribuição da pressão plantar. Diabetes Clin 1999;3:42-9

[2] Burutaran JM,"Baropodometría: estudio y aplicaciones", VI Congreso Nacional de la Asociación Española de Medicina y Cirugía del Pie. Abstract: 42, Oviedo, 1994.

[3] García Barbero, López Laserna J, Márquez López, Gascón Veguín, Martín Muñoz. "Baropodometría estática y dinámica. Nuestra casuística". XVI Congreso de la Asociación Española de Medicina y Cirugía del Pie. Abstract: 36, Oviedo, 1994

[4] Levy Benasuly A. E., Cortés Barragán J.M. "Ortopodología y Aparato Locomotor. Ortopedia de pie y tobillo". MASSON SA. Barcelona. España 2003 ed. São Paulo: Manole; 2003. p. 153-78.

[5] Betts RP, Franks CI, Duckworth T, Burke J. Static and dynamic foot-pressure measurements in clinical orthopaedics. Med Biol Eng Comp 1980; 18: 674-84.

[6] Vélez V. Martha K. "Posturología Clínica. Equilibrio corporal y salud" Pies. Sensor podal Págs. 75-80. Ediciones Universidad de las Américas. Quito Ecuador 2011.

[7] Kanatli U, Yetkin H, Cila E. Footprint and radiographic analysis of the feet. J Pediatr Orthopaedics 2001; 21:225-8.

[8] Tokars E, Motter AA, Moro AR, Gomes ZC. A influência do arco plantar na postura e no conforto dos calçados ocupacionais. Fisioterapia Brasil 2003; 4:157-62.

[9] Teodoro EC, Tomazini JE, Nascimento LF. Hálux valgo e pés planos: as forças plantares são iguais? Acta Ortop Bras 2007; 15:242-5

[10] Cavanagh PR, Rodgers MM. The arch index: a useful measure from footprints. J Biomech 1987;20:547-51.

[11] Rodriguez MD, Serrão JC, Ávila AO, Amadio AC. Aspectos antropométricos do pé humano: procedimentos de mensuração e relação com o crescimento na segunda infância. Rev Bras Postura Movimento 1998;2:15-27.

[12] Bordin D, De Giorgi G, Mazzocco G, Rigon F. Flat and cavus foot, indexes of obesity and overweight in a population of primary-school children. Minerva Pediatr 2001;53:7

[13] Cavanagh PR, Rodgers MM, Liboshi A. Pressure distribution under symptom-free feet during barefoot standing. Foot Ankle 1987; 7:262-76.

[14] Pérez García JM, López Soler JE, Martínez Villa J, Orrite C, Martínez Iturbe A, Herrera Rodríguez A., "Podómetro electrónico PDS 93. Contribución a la Baropodometría electrónica”. Rev. Med. Cir. Pie, 1995; IX, 2: 51-59 